\title{
Synaptic Modification by Correlated ActivitY: Hebb's Postulate Revisited
}

\author{
Guo-qiang $\mathrm{Bi}^{1}$ and Mu-ming Poo \\ Department of Molecular \& Cell Biology, University of California at Berkeley, Berkeley, \\ CA 94720-3200; email: mpoo@uclink4.berkeley.edu
}

Key Words Hebbian synapse, LTP, LTD, spike timing, input specificity

- Abstract Correlated spiking of pre- and postsynaptic neurons can result in strengthening or weakening of synapses, depending on the temporal order of spiking. Recent findings indicate that there are narrow and cell type-specific temporal windows for such synaptic modification and that the generally accepted input- (or synapse-) specific rule for modification appears not to be strictly adhered to. Spike timingdependent modifications, together with selective spread of synaptic changes, provide a set of cellular mechanisms that are likely to be important for the development and functioning of neural networks.

When an axon of cell A is near enough to excite cell B or repeatedly or consistently takes part in firing it, some growth or metabolic change takes place in one or both cells such that A's efficiency, as one of the cells firing B, is increased.

Donald Hebb (1949)

\section{INTRODUCTION}

Half a century since the publication of his famous treatise (Hebb 1949), Hebb's postulate of synaptic modification by correlated activity has become a cornerstone in our understanding of activity-dependent neural development and the cellular basis of learning and memory. This postulate was originally proposed by Hebb as a mechanism for the growth of "cell assembly," a hypothetical group of neurons that act briefly as a closed system after stimulation has ceased and that serve for the first stage of perception. Over the past several decades, Hebb's idea has been extended into various forms of correlation-based rules for synaptic modification and successfully used in many learning networks and in the analysis of activitydriven refinement of developing circuits (Stent 1973, Sejnowski \& Tesauro 1989, Brown et al 1990, Fregnac \& Bienenstock 1998, Sejnowski 1999). Here, we review

\footnotetext{
${ }^{1}$ Present address: Department of Neurobiology, University of Pittsburgh School of Medicine, Pittsburgh, PA 15261; e-mail: gqbi@ pitt.edu
} 
recent findings that shed new light on two aspects of Hebb's postulate: $(a)$ the temporal specificity in the correlated activity required for the induction of synaptic modification - the importance of temporal order in the pre- and postsynaptic spiking; and $(b)$ the spatial specificity in the induced synaptic changes - the notion that only the activated synapse becomes modified. Implications of these findings for the development and functioning of the nervous system are also addressed.

\section{TEMPORAL SPECIFICITY IN ACTIVITY-INDUCED SYNAPTIC MODIFICATION}

A central feature of Hebb's postulate is temporal specificity: The synaptic connection is strengthened only if cell A "takes part in firing" cell B, i.e. cell A fires before cell B. Such temporal specificity of activity-induced synaptic modification may be relevant for physiological functions, such as learning and memory, which are known to be temporally specific. Early studies have demonstrated a requirement for temporal contiguity in associative synaptic modification in rat hippocampus (Levy \& Steward 1983) and Aplysia ganglia (Hawkins et al 1983, Walters \& Byrne 1983). Recent experiments have revealed the importance of the temporal order of pre- and postsynaptic spiking for synaptic modification and have further defined the "critical windows" of spike timing, with precision on the order of milliseconds (Markram et al 1997, Magee \& Johnston 1997, Bell et al 1997, Debanne et al 1998, Zhang et al 1998, Bi \& Poo 1998, Egger et al 1999). The precise profile of critical windows appears to depend on the synapse type, and the underlying molecular mechanisms remain to be fully understood.

\section{Temporal Requirements for Associative Synaptic Modification}

Since the first description of long-term potentiation (LTP) in rabbit hippocampal formation (Bliss \& Lømo 1973, Bliss \& Gardner-Medwin 1973), similar synaptic potentiation has been found in many areas of the central and peripheral nervous systems of both vertebrates and invertebrates (Teyler \& DiScenna 1987, Brown et al 1990, Bliss \& Collingridge 1993, Buonomano \& Merzenich 1998, Milner et al 1998, Malenka \& Nicoll 1999). Certain forms of LTP in hippocampus have been shown to be cooperative and associative, properties relating directly to the theoretical construct of the Hebbian synapse. Cooperativity results from the existence of an intensity threshold for inducing LTP by tetanic stimulation (Bliss \& Lømo 1973, McNaughton et al 1978), whereas associativity usually refers to the induction of LTP in a "weak" input when it is coactive with a "strong" convergent input (Levy \& Steward 1979, Barrionuevo \& Brown 1983). In a sense, cooperatively induced LTP is a special case of associative LTP: both originate from the requirement in the synchrony of inputs for postsynaptic activation (Teyler \& DiScenna 1987).

Levy \& Steward (1983) studied in more detail the temporal specificity in associative synaptic modification. By stimulating a weak and a strong input from the 
entorhinal cortex to the denate gyrus of hippocampus, they found that associative induction of LTP did not require perfectly synchronous activation of the two pathways. Instead, the temporal order of the activation was crucial. LTP of the weak input could be induced when the strong input was activated concurrently with, or following the activation of, the weak input by as much as $20 \mathrm{~ms}$. When the temporal order was reversed, long-term depression (LTD) was induced. This and other early studies (Kelso \& Brown 1986, Gustafsson \& Wigström 1986) have clearly indicated the existence of a stringent temporal specificity in the activity-induced synaptic modification.

In the marine mollusk Aplysia, temporally specific synaptic modifications have been shown to account for classical conditioning in several reflex systems (Carew et al 1981, Hawkins et al 1983, Walters \& Byrne 1983). For example, in the siphon-withdrawal reflex, paired stimulation of the siphon sensory neuron [conditioned stimulus (CS)] and the tail nerve [unconditioned stimulus (US)] produces greater associative synaptic facilitation at sensorimotor connections when the CS precedes the US than if the temporal order is reversed (Hawkins et al 1983, Clark et al 1994). Such synaptic enhancement was considered non-Hebbian because the underlying cellular mechanism appeared to be purely presynaptic (Carew et al 1984). More recent studies, however, have shown postsynaptic involvement in associative synaptic facilitation of the same Aplysia system (Lin \& Glanzman 1994, Murphy \& Glanzman 1997). Temporally specific synaptic modification in invertebrates may thus be mediated by both presynaptic non-Hebbian and postsynaptic Hebbian mechanisms (Lechner \& Byrne 1998).

\section{The Role of Postsynaptic Spiking}

Low-frequency presynaptic stimulation coupled with concurrent postsynaptic depolarization (the "pairing protocol") can induce LTP in the hippocampus and different cortical areas (Kelso et al 1986, Sastry et al 1986, Wigström et al 1986, Malenka \& Nicoll 1999), demonstrating the importance of coincident activity in synaptic modification, as suggested by Hebb. However, this pairing protocol, with postsynaptic depolarization on the order of seconds to minutes, does not address the precise temporal specificity in the induction of LTP/LTD. Under natural conditions, postsynaptic neurons fire action potentials as their normal functional output, but whether these spikes are involved in inducing synaptic changes has been debated (for review, see Linden 1999). Active properties of dendrites (Regehr et al 1992, Lasser-Ross \& Ross 1992, Johnston et al 1996) allow the spike initiated at the axon hillock to back-propagate into dendrites (Stuart \& Sakmann 1994, Buzsáki et al 1996, Hoffman et al 1997). The back-propagating spike provides a precise signal capable of informing the synapses whether and precisely when the postsynaptic cell has fired, thus may play an active role in associative synaptic modification. The first definitive support for this notion came from recent studies in cortical and hippocampal slices (Markram et al 1997, Magee \& Johnston 1997). Using dual whole-cell recording from two interconnected layer 5 pyramidal 
neurons, Markram et al (1997) found that when the spikes were triggered $10 \mathrm{~ms}$ after the onset of excitatory postsynaptic potentials (EPSPs), LTP was induced by repetitive pairing of postsynaptic spiking (induced by current injection) with the EPSP, whereas when the temporal order of the spikes and EPSPs was reversed, LTD was induced. Magee \& Johnston (1997) found that back- propagating spikes in CA1 pyramidal neurons of hippocampus, when coupled immediately after the onset of subthreshold EPSPs, evoked a significantly higher $\mathrm{Ca}^{2+}$ influx at the synaptic site, resulting in LTP. In both studies, neither EPSPs nor postsynaptic spiking alone was sufficient to induce any synaptic modification. Thus, backpropagating postsynaptic spikes indeed can function as an associative signal for synaptic modification, and relative timing of pre- and postsynaptic activity is critical. Similar results have also been obtained in slice cultures (Debanne et al 1998), in developing Xenopus retinotectal projections in vivo (Zhang et al 1998), and in cultured hippocampal neurons (Bi \& Poo 1998).

\section{Critical Windows of Spike Timing for Synaptic Modification}

In cell culture, a critical window (Figure 1) for the induction of LTP/LTD has been characterized by systematically varying the spike timing (defined as the time interval between the onset of EPSP and postsynaptic spike) during repetitive correlated stimulation at a low frequency of $1 \mathrm{~Hz}$ (Bi \& Poo 1998). The window for modification is about $40 \mathrm{~ms}$ in width and is temporally asymmetric. Postsynaptic spiking within about $20 \mathrm{~ms}$ after presynaptic activation (positive intervals) results in LTP, whereas that within about $20 \mathrm{~ms}$ before presynaptic activation (negative intervals) results in LTD. The transition from LTD to LTP occurs within a few milliseconds of change in spike timing. It is interesting that an essentially identical window has been found in developing retinotectal system of Xenopus tadpoles (Zhang et al 1998). At Schaffer collateral synapses in the CA1 region of rat hippocampal slices, LTP/LTD can also be induced by similar correlated pre- and postsynaptic activation at a low frequency $(5 \mathrm{~Hz})$, with a characteristic critical window of spike timing that differs slightly from that found in culture. An additional LTD window was observed at positive intervals of 15-20 ms (Nishiyama et al 2000).

In hippocampal cultures, GABAergic transmission can also be modified by correlated pre- and postsynaptic spiking. Such modification exhibits a symmetric spiking-timing window that lasts about $50 \mathrm{~ms}$ and is independent of $N$-methyl-Daspartate receptors (NMDARs) (K Ganguly, M-m Poo, unpublished results). In the cerebellum-like structure of electric fish, synapses formed by parallel fiber onto Purkinje-like cells have a window opposite to that associated with the excitatory synapses described above: Spikes of positive intervals induce LTD and those of negative intervals induce LTP (Bell et al 1997). This opposite polarity in temporal specificity may be appropriate for the function this particular circuit, given that the Purkinje cell is an inhibitory projection neuron. In somatosensory cortex, excitatory neurons at different layers have markedly different windows. For synapses between layer 5 pyramidal neurons in somatosensory cortex, the 
$\Delta \mathrm{t}<0$

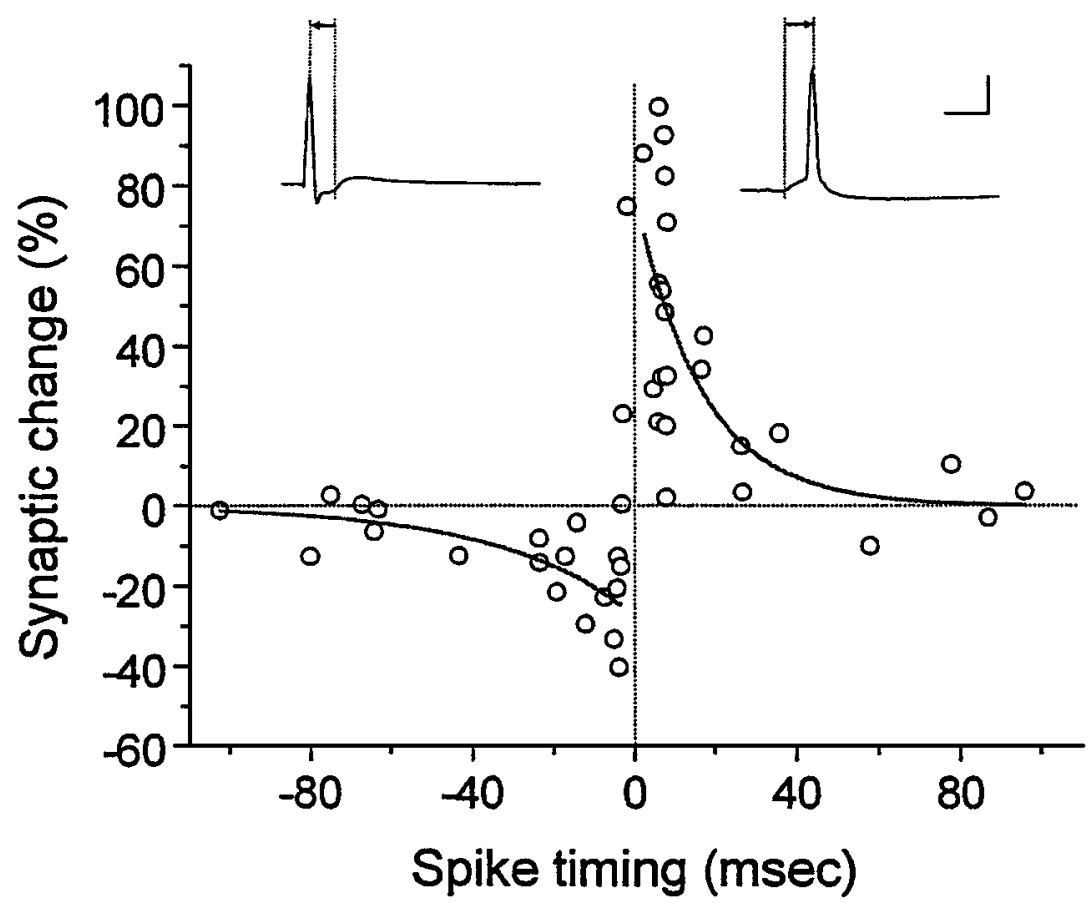

Figure 1 Critical window for synaptic modifications. Long-term potentiation (LTP)/longterm depression (LTD) were induced by correlated pre- and postsynaptic spiking at synapses between hippocampal glutamatergic neurons in culture. The percentage change in the excitatory postsynaptic current (EPSC) amplitude at 20-30 min after repetitive correlated spiking (pulses at $1 \mathrm{~Hz}$ ) was plotted against spike timing, which is defined as the time interval $(\Delta t)$ between the onset of the EPSP and the peak of the postsynaptic action potential during each pair of correlated spiking, as illustrated by the traces above. LTP and LTD windows are each fitted with an exponential function: $\left.\Delta W=A \times e^{(-\Delta \mathrm{t} / \tau}\right)$. For LTP and LTD, respectively, $A=0.777$ and $-0.273 ; \tau=16.8$ and $-33.7 \mathrm{~ms}$. Note that $\Delta W$ represents the total amount of change in synaptic strength after 60 pairs of correlated spiking. Assuming effective unitary change $\Delta w$ (due to a single pair) has similar time constants as those of $\Delta W$, i.e. $\Delta w=a \times e^{(\Delta \mathrm{t} / \tau)}$, thus $(1+A)=(1+a)^{60}$, yielding $a=$ 0.0096 and -0.0053 and the total areas under the unitary LTP and LTD curves $a \times \tau=$ 0.16 and 0.18 for LTP and LTD, respectively. Scales: $50 \mathrm{mV}, 10 \mathrm{~ms}$. [Data from Bi \& Poo (1998).] 
window is presumably of similar profile as that in Figure 1 (Markram et al 1997). However, synapses between layer 4 spiny stellate neurons appear to have a symmetric depression window (Egger et al 1999). Various spike-timing windows for synaptic modification reflect the diversity of synaptic machinery and may serve for specific functions of information processing at different stages of neural pathways.

\section{Mechanisms for the Detection of Coincidence and Temporal Order}

Previous studies on cellular mechanisms of LTP have addressed the role of the coincident pre- and postsynaptic activity in the induction of LTP (Bourne \& Nicoll 1993). In some brain regions, including the CA1 area of hippocampus, synaptic activation of postsynaptic NMDAR, a subtype of glutamate receptor channel, concurrently with membrane depolarization underlies the coincidence requirement for LTP (for reviews, see Collingridge et al 1983, Bourne \& Nicoll 1993). The depolarization-dependent removal of the $\mathrm{Mg}^{2+}$ block of the NMDAR (Mayer et al 1984, Nowak et al 1984, Jahr \& Stevens 1987) allows the channel to serve as a molecular detector for the coincidence of presynaptic activation (glutamate release) and postsynaptic depolarization. The resultant $\mathrm{Ca}^{2+}$ influx through the NMDAR triggers downstream kinases that lead to synaptic potentiation. Induction of LTD also requires coincident pre- and postsynaptic activation and, in some cases, NMDAR activation, although lower-level postsynaptic depolarization is needed (Linden \& Connor 1995, Bear \& Abraham 1996, Goda \& Stevens 1996). It is now generally believed that postsynaptic $\mathrm{Ca}^{2+}$ elevation is crucial for both LTP and LTD: Transient high-level $\mathrm{Ca}^{2+}$ elevation may lead to activation of certain protein kinases and LTP, whereas sustained low-level $\mathrm{Ca}^{2+}$ elevation may activate phosphatases and result in LTD (Lisman 1989, Malenka et al 1989, Malinow et al 1989, Silva et al 1992, Mulkey et al 1994, Yang et al 1999).

In principle, coincidence detection can occur at any converging point of signaling pathways where integration is nonlinear, as is the case for many biological processes. Thus, many components of signal transduction pathways may function as molecular coincidence detectors (Bourne \& Nicoll 1993). In Aplysia sensorimotor synapse, presynaptic adenylyl cyclase that is modulated by G-protein-coupled serotinin receptors and $\mathrm{Ca}^{2+} /$ calmodulin detects the coincidence of $\mathrm{Ca}^{2+}$ elevation (due to sensory neuron activity, or CS) and serotonin release (from the facilitating interneuron due to US). The resultant rise in cAMP is at least partly responsible for the associative synaptic facilitation at this synapse (Abrams et al 1991, Yovell et al 1992, Lechner \& Byrne 1998). In vertebrate brain, adenylyl cyclase is inhibited via G-protein by group II metobotropic receptors (mGluRs), which are known to be involved in several forms of LTP/LTD (Tzounopoulos et al 1998, Egger et al 1999, Yeckel et al 1999, Bortolotto et al 1999). Interaction between group II mGluR pathway and depolarization-induced $\mathrm{Ca}^{2+}$ signaling pathway is implicated in the coincidence detection at these forms of synaptic changes. Similarly, LTD in cerebellum and other forms of LTP/LTD in hippocampus require group I mGluRs that initiate $\mathrm{Ca}^{2+}$ release from intracellular stores via the activating 
phospholipase C (Ito et al 1982, Linden \& Connor 1995, Bear \& Abraham 1996, Bortolotto et al 1999). A synergistic release of $\mathrm{Ca}^{2+}$ from inositol-1,4,5triphosphate (IP3)-sensitive stores, evoked by synaptic activation of mGluRs, paired with back-propagating action potentials has been observed in the apical dendrites of CA1 pyramidal neurons (Nakamura et al 1999).

What cellular mechanisms are responsible for detecting the temporal order of pre- and postsynaptic spiking? Both LTP and LTD induced by correlated spiking depend on the activation of NMDARs (Markram et al 1997, Magee \& Johnston 1997, Debanne et al 1998, Zhang et al 1998, Bi \& Poo 1998), and LTD also requires functional L-type calcium channels (Bi \& Poo 1998). These requirements are similar to LTP and LTD induced by the conventional tetanic stimulation or pairing protocols. For correlated spiking with positive intervals, spiking following synaptic inputs apparently helps to open NMDARs, allowing high-level $\mathrm{Ca}^{2+}$ influx, thus LTP. With negative intervals, spiking allows low-level $\mathrm{Ca}^{2+}$ influx through voltage-gated $\mathrm{Ca}^{2+}$ channels, which was followed immediately by additional lowlevel $\mathrm{Ca}^{2+}$ influx due to NMDARs, resulting in LTD. Indeed, imaging studies have shown that $\mathrm{Ca}^{2+}$ elevation was supralinear when presynaptic stimulation immediately preceded the spike and was sublinear when the temporal order was reversed (Koester \& Sakmann 1998). Because the time constant of glutamate binding to NMDARs is much longer than 20 ms (Mayer et al 1984, Hollmann \& Heinemann 1994), the narrow window observed in different systems must be accounted for by additional mechanisms, e.g. nonlinearity in the activation of downstream effectors (e.g. calmodulin), or EPSP-induced, dendritic A-type $\mathrm{K}^{+}$channel inactivation (time constant $\sim 10 \mathrm{~ms}$ ) that permits synaptic invasion of back-propagating spikes (Hoffman et al 1997). Additional LTD at positive intervals found in hippocampal slices (Nishiyama et al 2000) may be due to differences in NMDAR properties, and $\mathrm{K}^{+}$channel activity, as well as the presence of local inhibitory inputs.

\section{IMPLICATIONS OF TEMPORAL SPECIFICITY}

The observation of stringent spike-timing windows highlights the potential role of individual spikes in synaptic modification (Linden 1999, Sejnowski 1999). The capability of synapses to detect precise timing of individual spikes is consonant with the idea that neural information may be encoded in spike timing (Perkel \& Bullock 1968, Rieke et al 1997). Temporally asymmetric windows, such as that shown in Figure 1, appear to be the most predominant form in different systems (see Table 1). These windows provide a basis for the formulation of a spike-based, temporally asymmetric Hebbian learning rule (Gerstner et al 1996, Gerstner \& Abbott 1997, Kempter et al 1999, Abbott \& Song 1999, Rao \& Sejnowski 2000, Mehta et al 2000, Senn et al 2000, Paulsen \& Sejnowski 2000). Here, we focus on several properties of this new learning rule, namely the spike- rather than rate-based computation, self-normalization, and temporal asymmetry. Its functional implications for classical conditioning and temporal-to-spatial conversion of information in neural networks are also discussed. 
TABLE 1 Spike timing $(\Delta t)$ for the induction of LTP/LTD in different systems ${ }^{\mathrm{a}}$

\begin{tabular}{llll}
\hline System & $\Delta \mathbf{t}$ LTD $(\mathbf{m s})$ & $\Delta \mathbf{t ~ L T P}(\mathbf{m s})$ & References \\
\hline Hippocampal dentate gyrus & $<0^{\mathrm{b}}$ & $0 \sim+20$ & Levy \& Steward 1983 \\
Hippocampal slice CA1 & None $^{\mathrm{c}}$ & $0 \sim+40$ & $\begin{array}{l}\text { Gustafsson \& Wigström } \\
1986, \text { Gustafsson et al }\end{array}$ \\
& & $0 \sim+15$ & 1987, Magee \& Johnston \\
& & & 1997 \\
& $-30 \sim 10 ;$ & $0 \sim+15$ & Nishiyama et al 2000 \\
Cortical slice layer 5 & $+15 \sim+20$ & & \\
Cerebellum-like structure & $0 \sim+50$ & $-50 \sim 0$ & Bell et al 1997 \\
Hippocampal slice culture & $-100 \sim-15^{\mathrm{d}}$ & $+15^{\mathrm{d}}$ & Debanne et al 1998 \\
Retino-tectal projection & $-20 \sim 0$ & $0 \sim+20$ & Zhang et al 1998 \\
Dissociated cell culture & $-30 \sim 0$ & $0 \sim+20$ & Bi \& Poo 1998 \\
Cortical slice layer 4 & $-10 \sim+10$ & None & Egger et al 1999 \\
\hline
\end{tabular}

${ }^{a}$ LTP, long-term potentiation; LTD, long-term depression.

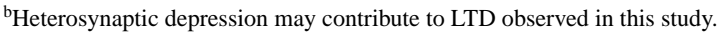

${ }^{c}$ LTD was not observed or tested in the experiments.

${ }^{\mathrm{d}}$ Single time points were tested for LTP/LTD in the experiments.

${ }^{\mathrm{e}}$ No significant LTP was observed in the experiment.

\section{Spike-Based, Temporally Asymmetric Learning Rule}

A “Microscopic" Learning Rule One distinct feature of the spike-based learning rule is that, in the computation of synaptic modification, it emphasizes the precise timing of each individual spike rather than the average rate of a population of spikes over a defined interval. Thus, this rule can be considered "microscopic," as opposed to earlier statistical or "macroscopic" rate-based formulations, e.g. the covariance and the Bienenstock-Cooper-Munro (BCM) rules (Sejnowski 1977b, Bienenstock et al 1982), in both of which only the average spike rate is important. Using the spike-based rule and assuming particular firing characteristics of pre- and postsynaptic neurons, one can derive different statistical rules (Kempter et al 1999, Senn et al 2000) and readily incorporate them into more conventional rate-based models. An exciting application of spike-based learning rules is in a new type of neural network models, the "pulsed neural networks" (Maass \& Bishop 1999), that use precise timing of individual spikes to encode information. Spike-timing or temporal coding may enable construction of more versatile and powerful networks because it provides larger coding capacity and easier handling of temporal information. However, whether the brain actually uses spike timing for coding information has been a long-standing issue in neuroscience (Perkel \& Bullock 1968, Rieke et al 1997, Singer 1999). The critical question is, timewise, how precisely can a neuron (or a group of neurons) detect synaptic inputs and 
generate as well as transmit spikes? The issues of precision and reliability of synaptic transmission, spike initiation, and propagation have been addressed by many theoretical and experimental studies (Calvin \& Stevens 1968, Bullock 1970, Bekkers et al 1990, Mainen \& Sejnowski 1995, Marsálek et al 1997, Stevens \& Zador 1998, Diesmann et al 1999). It is interesting that theoretical analysis suggests that in multilayer networks, synchronous spiking activity may propagate from one ensemble to the next while maintaining high precision of spike timing (Marsálek et al 1997, Diesmann et al 1999). Such "mode-locked" spike propagation in the brain is consistent with the highly synchronous activity found in many areas of the brain (Abeles et al 1993, deCharms \& Merzenich 1996, Riehle et al 1997, Roelfsema et al 1997, Dan et al 1998, Singer 1999). The existence of narrow windows of spike timing for synaptic modification indicates that synapses can indeed "read" information coded in the timing of pre- and postsynaptic spikes, with a precision on the order of a few milliseconds. Therefore, spike timing-based learning rules and the pulsed network models may provide powerful tools as well as insights into computational principles of the nervous system.

A “Self-Normalizing” Rule Hebb's original postulate described only activitydependent strengthening of a synapse. However, a complete learning rule must include both strengthening (LTP) and weakening (LTD) of synapses in order to avoid saturation, and weakening must be as specific as strengthening (rather than nonspecific decay) for serving long-term memories (Sejnowski 1977a, Stevens 1996). The new asymmetric Hebbian rule provides an immediate mechanism for self-normalization of synaptic weights and the output firing rate of a network (Kempter et al 1999, Abbott \& Song 1999, Senn et al 2000). Under normal conditions, such a balance is achieved if, in the spike-timing window of unitary modification (the effect of a single pairing event), the total integral of the LTD curve is equal to or slightly larger than that of the LTP curve. The data shown in Figure 1 indeed largely satisfy this requirement of self-normalization. In some synapses, the spike-timing windows for correlated spiking-induced modification appear not self-normalized (Egger et al 1999). It is possible that there is a low-level (undetectable) timing-independent LTD/LTP or activity-independent LTD/LTP that serves for nonspecific normalization of these synapses.

A “Temporally Asymmetric" Rule Perhaps the most attractive feature of the new learning rule is its sharp asymmetry in the window of spike timing. Association between two events of a specific temporal order can be established by asymmetric synaptic modification. This is fundamentally different from most formulations of Hebbian rules, in which only coincidence of activity (or associated between two concomitant events) was considered (Brown et al 1990). Hebb's original statement was remarkably accurate in implying the role of temporal order: A synaptic input is strengthened only when it "takes part in firing" the postsynaptic cell. Thus, a "true" Hebbian synapse behaves as a causality detector rather than a coincidence detector. Networks of neurons with such synapses can learn and predict sequences (Minai \& Levy 1993, Abbott \& Blum 1996, Roberts 1999) and form navigational 
maps that have been observed in hippocampus (Mehta et al 1997, Gerstner \& Abbott 1997, Mehta et al 2000). More generally, the predictive nature of the temporally asymmetric learning rule is directly related to the implementation of classical conditioning (see below).

\section{Classical Conditioning}

A hallmark of classical conditioning is the requirement of temporal contiguity: the conditioned stimulus (CS) must precede the unconditioned stimulus (US) during conditioning in order to elicit conditioned response. This ability to detect and remember causal relationships between events, to predict the about-to-happen, and to respond in advance are obviously advantageous to all animal species. Classical conditioning has been modeled successfully in the past by temporal-difference learning algorithm in reinforcement learning (Sutton \& Barto 1981, Tesauro 1986, Montague \& Sejnowski 1994, Moore et al 1998). It has been shown recently that the asymmetric Hebbian rule is mathematically equivalent to the temporaldifference learning algorithm (Roberts 1999, Rao \& Sejnowski 2000). Therefore, the asymmetric synaptic modification by correlated spiking provides a natural cellular mechanism of temporal-difference learning at the synaptic level.

Classical conditioning normally operates over a timescale on the order of seconds. In Aplysia siphon-withdrawal reflex, temporally specific synaptic enhancement at sensorimotor connections can be induced when stimulation of the tail (US) follows stimulation of the siphon sensory neuron (CS) within seconds (Hawkins et al 1983, Walters \& Byrne 1983, Clark et al 1994). In this case, cellular process with slow kinetics at the presynaptic terminal-the interaction between $\mathrm{Ca}^{2+}$ and adenylyl cyclase-provides a detection mechanism for a temporal order of sensory events (Yovell \& Abrams 1992). In vertebrate brain, processes such as synergistic release of postsynaptic $\mathrm{Ca}^{2+}$ stores by mGluR activation paired with back-propagating spikes (Nakamura et al 1999) may also provide temporally specific detection with a longer timescale than that mediated by NMDARs. Does correlated-spiking-induced synaptic modification found for hippocampal and cortical synapses, with the spike-timing window lasting tens of milliseconds, play a role in more elaborated forms of classical conditioning in vertebrates known to have temporal windows that last for seconds (Squire 1987, Thompson \& Krupa 1994)? Many different areas are likely to be involved in classical conditioning within the vertebrate brain, with polysynaptic and recurrent circuitry that can effectively extend the timescale of computation. For example, polysynaptic pathways may introduce long transmission delays so that a "remote" synapse may detect and become modified by two temporally distant stimuli that arrive at the site of modification within a narrow window of spike timing (Bi \& Poo 1999).

\section{Temporal-to-Spatial Conversion: Delay-Line Mechanism}

An essential process in learning and memory is the transformation of temporal information into spatially distributed information in the brain. Temporally varying 
sensory information, e.g. that associated with vision and audition, are processed and stored by the brain with remarkable precision (Carr 1993, Singer \& Gray 1995). The essential temporal information may be coded in the timing of transmitted spike trains (Rieke et al 1997, Singer 1999). In addition, inputs that are not explicitly temporal, e.g. odorant stimuli, may also be coded in spike timing (Hopfield 1995, Laurent 1997). Relative timing of spikes among neurons within functional ensembles may be used directly to represent internal states of functioning circuits (Riehle et al 1997). For synaptic modification to be a mechanism for long-term storage of memory, such information coded in spike timing must be converted into and stored as spatially distributed synaptic modifications in the brain. This requires that each synapse be sensitive to spike timing, as discussed above, and that a mechanism "assign" the temporal information specifically to different synaptic locations. One strategy for accomplishing this conversion relies on intrinsic synaptic properties (Buonomano \& Merzenich 1995), such as short-term plasticity and slow inhibitory currents that provide differential neuronal sensitivity to different spikes in an input train (Buonomano et al 1997). Another strategy is to take advantage of network architectures of "delay-lines" (Jeffress 1948, Braitenberg 1967, Tank \& Hopfield 1987) that have been demonstrated in several systems where the delay is due to axonal conduction of action potentials (Carr 1993). Recently, we have shown that in networks of cultured neurons, polysynaptic transmission pathways may form functional delay-lines (Bi \& Poo 1999). Repetitive paired-pulse stimulation of one neuron results in correlated spiking and LTP/LTD at remote synaptic sites, when the interpulse interval matches the delay difference between convergent pathways leading to the remote sites (Bi \& Poo 1999). Because neurons in such cultures tend to hyper-innervate each other, these polysynaptic pathways in culture may be analogous to chains of synchronously firing cell ensembles in vivo that have been proposed for cortical processing (Abeles 1991). With such delay-lines and spike-timing dependent LTP/LTD, information coded in the spike train may be stored at selective connections between cell ensembles in the form of long-term synaptic modification.

\section{Activity-Driven Refinement of Developing Networks}

Since the early works of Hubel and Wiesel on the effects of monocular deprivation (Wiesel \& Hubel 1963) and artificial strabismus (Hubel \& Wiesel 1965) on the developing visual system, it has been generally recognized that neuronal activity is critical for refining the connections in the brain (for reviews, see Katz \& Shatz 1996, Constantine-Paton et al 1990). There is also evidence that activity may provide an instructive (rather than permissive) role. For example, ocular dominance columns in the cortex were abolished if artificially synchronized activity was imposed to both eyes, whereas imposing asychonous activity between the eyes of the same frequency was not effective (Stryker \& Strickland 1984). Development of orientation selectivity and responsiveness of visual cortical neurons can also be reduced by artificial stimulation of optic nerves (Weliky \& Katz 1997). Although 
patterned visual experience may not be necessary for the initial development of either ocular dominance or orientation maps (Horton \& Hocking 1996, Crair et al 1998, Crowley \& Katz 1999), the endogenous patterns of spontaneous activity (Wong et al 1995, Penn et al 1998), in the retina as well as in higher visual areas, could still play a role.

In addressing the cellular mechanism by which asynchronous activity between the two eyes drives the formation of ocular dominance columns, Stent (1973) proposed an extension of Hebb's postulate: Synchronous activity strengthens the synapse, whereas asynchronous activity weakens the synapse. This simple rule of "neurons that fire together wire together" can explain activity-dependent competitive interactions between converging inputs on the same postsynaptic neurons. Synchronous spiking is more likely to occur for inputs from the same eye; thus, there is eye-specific segregation of inputs in lateral geniculate nucleus and in the visual cortex. Correlation of spiking is stronger for inputs from neighboring neurons in the same retina; thus, a crude retinotopic map (presumably formed initially by chemical cues) can be refined into a more fine-grained map (Constantine-Paton et al 1990). Simple synchrony- or correlation-based rules have also been successfully used in modeling activity-driven development of simple receptive fields and the ordered arrangement of ocular dominance and orientation columns (Miller et al 1989, Miller 1994), as well as ocularly matched orientation and ocular dominance maps (Erwin \& Miller 1998).

The finding of spike-timing-dependent modifications raises several questions. Is a simple correlation-based Hebbian rule a realistic or complete description of activity-driven processes? Are there activity-dependent processes other than the modification of synaptic strength that are correlation based but spike-timing independent? Does introduction of spike-timing dependency into correlation-based rule offer new features for the more complex aspects of circuit developments? It is interesting to note that spike-timing-dependent rules have been used successfully in modeling the development of fine temporal discrimination in the auditory system (Gerstner et al 1996) and direction-sensitive receptive field organization of mammalian visual cortical neurons (Rao \& Sejnowski 2000).

\section{SPATIAL SPECIFICITY IN ACTIVITY-INDUCED SYNAPTIC MODIFICATION}

Although not explicitly stated in Hebb's postulate, it is generally assumed that Hebbian synaptic modifications are synapse (or input) specific_-only synapses experiencing correlated activity become modified. Input specificity was indeed observed in many studies of LTP/LTD (Andersen et al 1977, Lynch et al 1977, Dudek \& Bear 1992, Mulkey \& Malenka 1992, Nicoll \& Malenka 1997). Thus, Hebbian rule is regarded as a "local" rule, in which individual synapses are independent of one another. Although the simplicity of this local rule has been 
TABLE 2 Spread of LTP/LTD observed in different systems ${ }^{\mathrm{a}}$

\begin{tabular}{lll}
\hline Induction & Spread $^{\text {b }}$ & Systems (References) \\
\hline LTP & $\begin{array}{c}\text { Presynaptic lateral } \\
\text { (diverging outputs) }\end{array}$ & $\begin{array}{l}\text { Hippocampal slice CA1 (Schuman \& Madison 1994) } \\
\text { Hippocampal slice culture (Bonhoeffer et al 1989) } \\
\text { Visual cortex slice (Kossel et al 1990) }\end{array}$ \\
& & Hippocampal culture (Tao et al 2000) \\
& Postsynaptic lateral & Hippocampal slice CA3 (Bradler \& Barrioneuvo 1989) \\
& (converging inputs) & Hippocampal slice CA1 (Muller et al 1995) \\
& Hippocampal slice culture (Engert \& Bonhoeffer 1997) \\
& Hippocampal aspinous interneurons (Cowan et al 1998) \\
& Back propagation & Hippocampal culture (Tao et al 2000) \\
Presynaptic lateral & Hippocampal culture (Fitzsimonds et al 1997) \\
& Postsynaptic lateral & Hippocampal slice CA1 (Muller et al 1995, \\
& Staubli \& Ji 1996, Nishiyama et al 2000) \\
& & Hippocampal aspinous interneurons (Cowan et al 1998) \\
& & Hippocampal interneurons (McMahon \& Kauer 1997) \\
& & Hippocampal culture (Fitzsimonds et al 1997) \\
& & Hippocampal culture (Fitzsimonds et al 1997) \\
\hline
\end{tabular}

${ }^{\mathrm{a}} \mathrm{LTP}$, long-term potentiation; LTD, long-term depression.

${ }^{\mathrm{b}} \mathrm{See}$ text and Figure 2 for definitions.

beneficial for many neural network models (Brown et al 1990, Rolls \& Treves 1998), there is now increasing evidence that activity-induced synaptic modification may be accompanied by changes in some other synapses within a neural network (see Table 2).

\section{Heterosynaptic LTD}

Early studies of LTP in the CA1 region of hippocampus have shown a depression of unstimulated commissural-CA1 synapses following LTP-inducing tetanic stimulation of Schaffer collaterals (Lynch et al 1977, Dunwiddie \& Lynch 1978). This phenomenon, termed heterosynaptic LTD, has since been observed in the cortex (Tsumoto \& Suda 1979, Hirsch et al 1992), dentate gyrus (Levy \& Steward 1979, Abraham \& Goddard 1983), and the CA3 area (Bradler \& Barrioneuvo 1989) of hippocampus, as well as at embryonic neuromuscular junctions in culture (Lo \& Poo 1991). The conditions for the induction and expression of heterosynaptic LTD vary between different systems, but appear to be closely related to that for homosynaptic LTD (for reviews, see Linden \& Connor 1995, Bear \& Abraham 1996). A moderate rise in postsynaptic $\mathrm{Ca}^{2+}$, through influx mediated by NMDARs and other $\mathrm{Ca}^{2+}$ channels as well as through $\mathrm{Ca}^{2+}$ release from internal stores, has been implicated in the induction mechanism, although the signaling pathways downstream of $\mathrm{Ca}^{2+}$ elevation and the mechanism of expression remain 
largely unknown. Heterosynaptic LTD induced by the induction of LTP represents perhaps a special case of more general non-local effects of synaptic modification (see below).

\section{Spread of LTP/LTD in Slices}

Although heterosynaptic LTD indicates the existence of interaction between distant synapses, it is not considered a violation of input specificity because changes at nonstimulated sites are opposite in polarity from those at induction sites. However, exceptions to this rule have been observed since the early days of LTP studies (for review, see Teyler \& DiScenna 1987). For example, in area CA3 of hippocampus, mossy fiber tetanization leads to heterosynaptic LTP, as reflected in an increased field potential evoked by other converging but independent inputs, in addition to the conventional homosynaptic LTP (Yamamoto \& Chujo 1978, Misgeld et al 1979). This heterosynaptic LTP may be caused by an increase in the polysynaptic component of CA3 field potentials, resulting from enhanced transmission among CA3 neurons (Higashima \& Yamamoto 1985). It is interesting that Bradler \& Barrioneuvo (1989) found that among three inputs to the CA3 area, tetanus-induced LTP in the mossy fiber input was accompanied by heterosynaptic LTP of Schaffer collateral and fimbrial responses, whereas LTP in the Schaffer pathway was associated with the LTP of fimbrial responses and LTD of mossy fiber responses. In contrast, LTP induced in the fimbrial response was input specific.

More recent works have revealed different forms of "breakdown" of synapse specificity of LTP in the CA1 region of hippocampus. In slice cultures, Bonhoeffer et al (1989) found that LTP induced by pairing presynaptic stimulation with postsynaptic depolarization is accompanied by potentiation at synapses made by the stimulated fibers on neighboring postsynaptic cells. Similar "spread" of potentiation was also observed in the visual cortex, where the spread of potentiation was shown to occur only for synapses made by the stimulated, but not unstimulated, inputs (Kossel et al 1990). A closer examination using local perfusion indicated that, in hippocampal slice cultures, LTP can spread to other inputs on the same postsynaptic cell as long as the unstimulated synapses are within $\sim 70$ $\mu \mathrm{m}$ of the site of LTP induction (Engert \& Bonhoeffer 1997). Also observed at excitatory synapses was postsynaptic spread of LTP onto aspinous dendrites of interneurons whose somata were located in the CA1 pyramidal cell layer (Cowan et al 1998). It is interesting that pairing-induced LTP in CA1 pyramidal cells of acute hippocampal slices also spread to synapses made by the same set of afferent fibers onto neighboring postsynaptic cells (Schuman \& Madison 1994). Taken together, these studies revealed two forms of spread of LTP. In one form, synaptic sites of induction and spread are apparently made by the same (group of) presynaptic axons on different postsynaptic cells (Bonhoeffer et al 1989, Kossel et al 1990, Schuman \& Madison 1994). In the other form, the synapses of induction and spread are on the same postsynaptic cell but made by different presynaptic axons (Engert \& Bonhoeffer 1997, Cowan et al 1998). For convenience, we 
define these two forms presynaptic spread and postsynaptic spread, respectively (Figure 2). Note that presynaptic spread can only be defined unequivocally when the stimulation is applied to a single presynaptic neuron. Thus, the cases using extracellular stimulation of afferent fibers (Bonhoeffer et al 1989, Kossel et al 1990, Schuman \& Madison 1994) can only be regarded as consistent with the definition of presynaptic spread.

Several studies of conventional homosynaptic LTD have also suggested a breakdown of synapse specificity under different conditions. In CA1, homosynaptically induced LTD was found to be associated with a heterosynaptic reversal of the LTP previously induced in a separate pathway, and the effect was absent for naïve inputs and dependent on both NMDAR and calcineurin (Muller et al 1995). Another study, however, suggested that LTD at one of two independent Schaffercollateral/commissural inputs may spread to the other (presumably naïve) input when the level of synaptic activation during low-frequency stimulation was strong enough to induce postsynaptic spiking (Staubli \& Ji 1996). Spread of a different form of LTD has been observed in excitatory synapses onto GABAergic interneurons in the CA1 area of hippocampus: Tetanic stimulation of the input fiber resulted in LTD that spread to neighboring excitatory synapses onto the same postsynaptic interneurons (McMahon \& Kauer 1997). In all these cases, only postsynaptic spread has been examined. These results differ from conventional heterosynaptic LTD in that the change at the induction pathway is also LTD rather than LTP.

The issue of input specificity of LTP/LTD induced by correlated pre- and postsynaptic spiking has been examined recently for Schaffer collateral-CA1 synapses in hippocampal slices (Nishiyama et al 2000). It was found that correlated activity of positive intervals induces input-specific homosynaptic LTP, whereas that of negative intervals induces LTD that spreads to heterosynaptic unstimulated inputs. Reduction of postsynaptic $\mathrm{Ca}^{2+}$ influx by partial blockade of NMDA receptors resulted in a conversion of LTP to LTD and a "breakdown" of input specificity, with LTD appearing at heterosynaptic inputs. The induction of LTD at homo- and heterosynaptic sites requires functional ryanodine receptors and $\mathrm{IP}_{3}$ receptors $\left(\mathrm{IP}_{3} \mathrm{R}\right)$, respectively. Functional blockade or genetic deletion of type $1 \mathrm{IP}_{3} \mathrm{R}$ led to a conversion of LTD to LTP and elimination of heterosynaptic LTD, whereas blocking ryanodine receptors eliminates only homosynaptic LTD. These results indicate that both the polarity and input specificity of activity-induced synaptic modifications are tightly regulated by postsynaptic $\mathrm{Ca}^{2+}$, derived from $\mathrm{Ca}^{2+}$ influx and differential release of $\mathrm{Ca}^{2+}$ from internal stores. Therefore, input specificity should be viewed not as an intrinsic property associated with LTP/LTD but as a dynamic variable linked to the spread of dendritic $\mathrm{Ca}^{2+}$ elevation.

\section{Selective Spread of LTP/LTD in Cell Cultures}

Recent studies on synaptic plasticity in cell cultures have revealed extensive but selective spread of both LTP and LTD from the site of induction to other synapses 


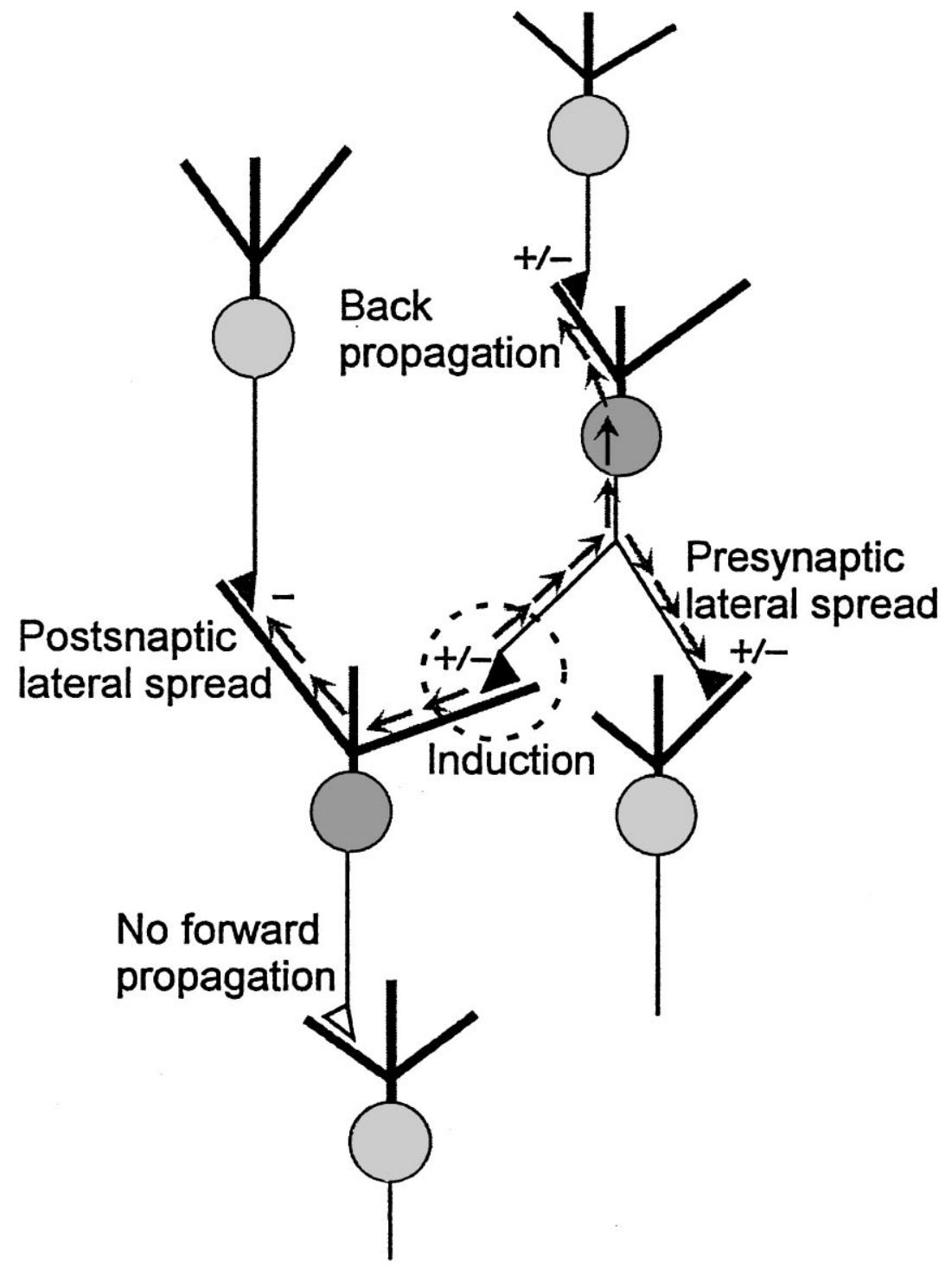

Figure 2 Different types of spread of long-term potentiation (LTP) and long-term depression (LTD). Induction of LTP/LTD at a synapse between glutamatergic neurons (black triangle in dashed circle) leads to the spread of LTP/LTD (marked as +/-) to other synapses in the network. Arrows indicate direction of signaling underlying the spread of LTP/LTD to divergent outputs of the presynaptic neuron (presynaptic lateral spread) and synapses on the dendrites of presynaptic neuron (back propagation), as well as the spread of LTD to convergent inputs on the postsynaptic neuron (postsynaptic lateral spread). Spread of LTP/LTD to the output of postsynaptic neurons (forward propagation) has not been observed. 
in a network. In Xenopus nerve-muscle cultures, LTD induced by postsynaptic elevation of $\mathrm{Ca}^{2+}$ can spread to synapses made by the same presynaptic neuron on other myocytes, apparently by signaling within the cytoplasm of the presynaptic neuron (Cash et al 1996). In small networks of cultured hippocampal neurons, LTD induced at synapses between two glutamatergic neurons can spread to other synapses made by divergent outputs of the same presynaptic neuron (presynaptic lateral propagation) and to synapses made by other convergent inputs on the same postsynaptic cell (postsynaptic lateral propagation). Furthermore, LTD can also spread in a retrograde direction to depress synapses on the dendrite of the presynaptic neuron (back propagation) but not in anterograde direction (forward propagation) to depress output synapses of the postsynaptic neuron (Fitzsimonds et al 1997) (see Figure 2). It is interesting that in the same culture system, LTP induced at synapses between two glutamatergic neurons by correlated spiking exhibits a selective spread only to those synapses associated with the presynaptic neuron (i.e. both lateral and back propagation), not to those associated with the postsynaptic neuron (no lateral or forward propagation) (Tao et al 2000). In addition, the presynaptic lateral propagation of LTP is target cell specific: Divergent outputs to GABAergic postsynaptic neurons are not modified. This specificity is similar to the target specificity found in the induction of LTP in both cultures and slices (McMahon \& Kauer 1997, Maccaferri et al 1998, Bi \& Poo 1998, Reyes et al 1998, Schinder et al 2000). Finally, neither LTP nor LTD was found to spread further up- or downstream beyond the immediate neighboring synapses (Fitzsimonds et al 1997, Tao et al 2000). Although findings in cell culture may represent an exaggeration of phenomena occurring in vivo, the simplicity of the culture system enables investigation of cellular processes and network principles that may be present to varying degrees in more complex neural systems.

\section{Development of Input Specificity}

Recent studies of activity-induced synaptic modification in the developing Xenopus retinotectal system have suggested a cellular basis for the input specificity associated with LTP (H-z Tao, L Zhang, F Engert, M-m Poo, unpublished results). The induction of LTP at retinotectal synapses by theta burst stimulation of the retinal ganglion cells was not input-specific: LTP induced in one retinal ganglion cell pathway spreads to other converging retinal ganglion cell inputs on the same tectal neuron. Inputs on other adjacent tectal neurons were not affected, which suggests that the spread of potentiation was due to signaling within the postsynaptic cytoplasm. As the animal matures, LTP of retinotectal synapses induced by the same theta burst activity becomes input specific, a change that correlates with increased complexity of the dendritic arbor of tectal neurons and more restricted distribution of dendritic $\mathrm{Ca}^{2+}$ elevation evoked by retinal inputs. In contrast to that found for theta burst activity, LTP induced by low-frequency correlated pre- and postsynaptic spiking was input specific throughout the development. These results showed that a "break-down" of input specificity of 
activity-induced LTP can occur during in vivo development. The extent of the spread of synaptic potentiation, which correlates with spatial distribution of dendritic $\mathrm{Ca}^{2+}$ elevation, depends on the developmental stage as well as the pattern of synaptic activity.

\section{IMPLICATIONS OF SPATIAL SPECIFICITY (OR LACK OF IT)}

\section{Long-Range Signaling in and Across Neurons}

The spread of LTP/LTD and heterosynaptic LTD indicates that there are interactions among different synapses by long-range signaling either within the neuronal cytoplasm or across the neurons through the extracellular space. It has been suggested that membrane-permeable diffusible factors are responsible for retrograde signaling during the induction of LTP and LTD (for review, see Bliss \& Collingridge 1993, Fitzsimonds \& Poo 1998). These diffusible factors may affect other synapses close to the sites of induction. Schuman \& Madison (1994) have suggested that nitric oxide may mediate the spread of LTP in hippocampus because inhibition of nitric oxide synthase in the postsynaptic cell blocked induction of LTP as well as its spread. However, a different signal triggered by the retrograde signal associated with LTP (e.g. nitric oxide) could be responsible for the spread of potentiation, and the signal could be confined intracellularly.

The extensive but highly selective spread of LTP/LTD found in culture argues for the existence of a rapid long-range intracellular signaling within the cytoplasm, with a speed of at least a few micrometers per second. This requires cytoskeletonbased axonal transport or regenerative waves as a means of signaling. Induction of LTP/LTD may generate $\mathrm{Ca}^{2+}$ waves (Berridge 1998) in either pre- or postsynaptic neuron and, through its diverse downstream effectors, results in either heterosynaptic LTD or spread of LTP/LTD. At Schaffer collateral-CA1 synpases, LTD induced by correlated pre- and postsynaptic activation (of negative intervals) spreads to unstimulated inputs to the same CA1 neuron (Nishiyama et al 2000). This spread was abolished by postsynaptic loading of a specific function-blocking antibody of type $1 \mathrm{IP}_{3} \mathrm{R}$ and was absent in hippocampal slices obtained from $\mathrm{IP}_{3} \mathrm{R}$-deficient mice, consistent with the notion that an $\mathrm{IP}_{3} \mathrm{R}$-dependent wave may be responsible for postsynaptic spread of LTD. Another second-messenger cAMP is known to be involved in different forms of synaptic plasticity and can diffuse rapidly in neuronal cytoplasm (Hempel et al 1996). Local elevation of cAMP/PKA activity in a developing neuron has been shown to exert long-range actions on distant parts of the neuron (Zheng et al 1994). In Aplysia, restricted application of serotonin to the cell bodies of sensory neurons can cause long-term enhancement at synaptic connections of the same sensory neuron to distant motoneurons 
(Clark \& Kandel 1993, Emptage \& Carew 1993). Thus, cAMP or its downstream effectors can serve for cytoplasmic signaling involved in the spread of synaptic modification.

Long-range cytoplasmic signaling may also involve motor protein-based transport of vesicular membranes (Vale et al 1985, Vallee \& Bloom 1991, Kuznetsov et al 1992, Bi et al 1997). Fast axonal transport of vesicles carrying internalized retrograde factors (e.g. neurotrophins) or vesicle-associated cytoplasmic effectors triggered by the induction of LTP/LTD may spread the signal for potentiation/depression within the cytoplasm. Restricted application of glutamate to somata of identified presynaptic neurons led to LTP of its output synapses, and this LTP can be blocked by pretreatment of microtubule-depolymerizing reagent colchicine (Lux \& Veselovsky 1994). However, depolymerization of microtubule may also disrupt the normal structure of endoplasmic reticulum that supports the propagation of $\mathrm{Ca}^{2+}$ waves. Axotomy of postganglionic fibers leads to regression of synaptic inputs from preganglionic axon, a phenomenon that can be simulated by local chochicine block of the postganglionic fiber and can be prevented by supplying an exogenous neurotrophin nerve growth factor (Purves 1975). In hippocampal cell cultures, brain-derived neurotrophic factor induces synaptic potentiation by elevating transmitter secretion in a target cell-specific manner (Schinder et al 2000), i.e. only for those terminals innervating glutamatergic but not GABAergic neurons. This specificity has also been seen in the induction and spread of LTP in the same cultures (Bi \& Poo 1998, Tao et al 2000). Thus, brain-derived neurotrophic factor may also be a good candidate for the cytoplasmic signal for presynaptic spread of LTP.

\section{Non-Local Rules in Neural Networks}

Back-Propagation Although synapse specificity has been a "central dogma" in the concept of synaptic modification, a popular network model of supervised learning adopted a non-local rule, with which signals for synaptic modification can propagate backward through connections in multilayer networks (Rumelhart et al 1986a,b). This "back-propagation" algorithm, which uses the "error" of the output of a neuron to proportionally adjust the synaptic strength of its inputs, has been extremely powerful in training simple artificial networks to perform a wide range of tasks. The back-propagation algorithm has been considered nonbiological because it directly violates the rule of synapse specificity and is inconsistent with the known direction of signaling in neurons, i.e. from the input to the output (cf Rolls \& Treves 1998). It is interesting that back propagation of LTP/LTD observed in cell cultures appears to fit qualitatively the requirement for back propagation of errors: If the output synapses of a neuron undergo LTP/LTD, then its input synapses undergo similar changes. However, it is not clear whether the spreading LTP/LTD can be integrated by the neuron, analogous to the linear summation of error signals in the back-propagation algorithm. In addition, the spread 
of LTP/LTD in culture does not appear to go beyond the immediate layer of neurons involved in the induction of LTP/LTD.

The Unit of Synaptic Modification The exclusively "presynaptic" pattern of LTP spread in culture (Tao et al 2000) suggests that many output synapses of a single excitatory neuron may be modified as an integral unit in activity-dependent synaptic plasticity, with changes at each synapse affecting the others. Such coordinated changes among specific sets of synapses may help to recruit new cells into an existing ensemble and contribute to the development of synchronous firing in the cortex. Furthermore, both the induction and the presynaptic spread of LTP are target cell specific (do not occur at glutamatergic synapses made onto GABAergic postsynaptic neurons), whereas GABAergic synapses may be modified directly by correlated activity and indirectly by spread of LTP/LTD from neighboring sites (Fitzsimonds et al 1997, Aizenman et al 1998, Tao et al 2000; K Ganguly, M-m Poo, unpublished results). Target cell-specific induction and spread of LTP/LTD indicate that the unit of synaptic modification is the subset of presynaptic nerve terminals innervating the same postsynaptic cell type. The ability of GABAergic synapses to be modified suggests an active role for these inhibitory connections in the learning and memory function of neural circuits. Finally, we note that for converging inputs in networks of dissociated hippocampal neurons in culture and in CA1 pyramidal neurons in hippocampal slices, input specificity appears to be more strictly followed for LTP than for LTD. The implication of such asymmetry in input specificity in the development and functioning of neural network remains to be investigated.

\section{CONCLUDING REMARKS}

The induction and expression of LTP/LTD represent only the initial consequence of correlated activity. A myriad of subsequent events, including local activation of enzymes, posttranslational modification of proteins, and changes in protein synthesis and gene expression, occur in both pre- and postsynaptic cells, leading to long-lasting structural and functional alterations of the synapses as well as the entire neuron (Milner et al 1998). The existence of long-range and selective signaling within the neuron, as examplified by the selective spread of LTP/LTD, argues that activity-induced local synaptic modification must be considered as an integral part of global neuronal changes. The existence of reciprocal and selective transsynaptic signaling between neurons further suggests that synaptic and neuronal plasticity must be considered within the context of the interacting neurons in the neural network.

Synaptic modification by correlated activity was proposed by Hebb as a mechanism for the formation of "cell assembly," a network consolidated by patterned activities, which serves as a fundamental unit for perceptual functions of the brain. Although Hebb's original notion that development of the network is intimately 
linked to the perceptual function of the network remains to be validated, his postulate on synaptic modification has become a recurrent theme for understanding the synaptic basis underlying both activity-driven refinement of developing networks and learning and memory functions of mature networks. Developmental refinement may indeed use synaptic mechanisms similar to that used for learning and memory. In the spirit of Hebb, one may further ask whether the development of new networks is a basis of learning and memory in mature brain and, conversely, whether the structure of mature brain is but a reflection of perceptual experience during its early development.

\section{Visit the Annual Reviews home page at www.AnnualReviews.org}

\section{LITERATURE CITED}

Abbott LF, Blum KI. 1996. Functional significance of long-term potentiation for sequence learning and prediction, Cereb. Cortex 6:406-16

Abbott LF, Song S. 1999. Temporally asymmetric Hebbian learning, spike timing and neuronal response variability. In Advances in Neural Information Processing Systems, ed. MS Kearns, SA Solla, DA Cohn, 11:69-75. Cambridge, MA: MIT Press

Abeles M. 1991. Corticonics. Cambridge, UK: Cambridge Univ. Press

Abeles M, Bergman H, Margalit E, Vaadia E. 1993. Spatiotemporal firing patterns in the frontal cortex of behaving monkeys. J. Neurophysiol 70:1629-38

Abraham WC, Goddard GV. 1983. Asymmetric relationships between homosynaptic long-term potentiation and heterosynaptic long-term depression. Nature 305:71719

Abrams TW, Karl KA, Kandel ER. 1991. Biochemical studies of stimulus convergence during classical conditioning in Aplysia: dual regulation of adenylate cyclase by $\mathrm{Ca}^{2+} /$ calmodulin and transmitter. J. Neurosci. 11:2655-65

Aizenman CD, Manis PB, Linden DJ. 1998. Polarity of long-term synaptic gain change is related to postsynaptic spike firing at a cerebellar inhibitory synapse. Neuron 21:82735
Andersen P, Sundberg SH, Sveen O, Wigström H. 1977. Specific long-lasting potentiation of synaptic transmission in hippocampal slices. Nature 266:736-37

Barrionuevo G, Brown TH. 1983. Associative long-term potentiation in hippocampal slices. Proc. Natl. Acad. Sci. USA 80:734751

Bear MF, Abraham WC. 1996. Long-term depression in hippocampus. Annu. Rev. Neurosci. 19:437-62

Bekkers JM, Richerson GB, Stevens CF. 1990. Origin of variability in quantal size in cultured hippocampal neurons and hippocampal slices. Proc. Natl. Acad. Sci. USA 87:535962

Bell CC, Han VZ, Sugawara Y, Grant K. 1997. Synaptic plasticity in a cerebellum-like structure depends on temporal order. Nature 387:278-81

Berridge MJ. 1998. Neuronal calcium signaling. Neuron 21:13-26

Bi G-q, Morris RL, Liao GC, Alderton JM, Scholey JM, Steinhardt RA. 1997. Kinesinand myosin-driven steps of vesicle recruitment for $\mathrm{Ca}^{2+}$-regulated exocytosis. J. Cell Biol. 138:999-1008

Bi G-q, Poo M-m. 1998. Synaptic modifications in cultured hippocampal neurons: Dependence on spike timing, synaptic strength, and postsynaptic cell type. J. Neurosci. 18:10464-72 
Bi G-q, Poo M-m. 1999. Distributed synaptic modification in neural networks induced by patterned stimulation. Nature 401:792-96

Bienenstock EL, Cooper LN, Munro PW. 1982. Theory for the development of neuron selectivity: orientation specificity and binocular interaction in visual cortex. J. Neurosci. 2:32-48

Bliss TV, Collingridge GL. 1993. A synaptic model of memory: long-term potentiation in the hippocampus. Nature 361:31-39

Bliss TV, Gardner-Medwin AR. 1973. Longlasting potentiation of synaptic transmission in the dentate area of the unanaestetized rabbit following stimulation of the perforant path. J. Physiol. 232:357-74

Bliss TV, Lømo T. 1973. Long-lasting potentiation of synaptic transmission in the dentate area of the anaesthetized rabbit following stimulation of the perforant path. J. Physiol. 232:331-56

Bonhoeffer T, Staiger V, Aertsen A. 1989. Synaptic plasticity in rat hippocampal slice cultures: local "Hebbian" conjunction of pre- and postsynaptic stimulation leads to distributed synaptic enhancement. Proc. Natl. Acad. Sci. USA 86:8113-17

Bortolotto ZA, Fitzjohn SM, Collingridge GL. 1999. Roles of metabotropic glutamate receptors in LTP and LTD in the hippocampus. Curr. Opin. Neurobiol. 9:299-304

Bourne HR, Nicoll R. 1993. Molecular machines integrate coincident synaptic signals. Cell 72(Suppl.):65-75

Bradler JE, Barrioneuvo G. 1989. Long-term potentiation in hippocampal CA3 neurons: tetanized input regulates heterosynaptic efficacy. Synapse 4:132-42

Braitenberg V. 1967. Is the cerebellar cortex a biological clock in the millisecond range? Prog. Brain Res. 25:334-46

Brown TH, Kairiss EW, Keenan CL. 1990. Hebbian synapses: biophysical mechanisms and algorithms Annu. Rev. Neurosci. 13:475511

Bullock TH. 1970. The reliability of neurons. J. Gen. Physiol. 55:565-84
Buonomano DV, Hickmott PW, Merzenich MM. 1997. Context-sensitive synaptic plasticity and temporal-to-spatial transformations in hippocampal slices. Proc. Natl. Acad. Sci. USA 94:10403-8

Buonomano DV, Merzenich MM. 1995. Temporal information transformed into a spatial code by a neural network with realistic properties. Science 267:1028-30

Buonomano DV, Merzenich MM. 1998. Cortical plasticity: from synapses to maps. Annu. Rev. Neurosci. 21:149-86

Buzsáki G, Penttonen M, Nádasdy Z, Bragin A. 1996. Pattern and inhibition-dependent invasion of pyramidal cell dendrites by fast spikes in the hippocampus in vivo. Proc. Natl. Acad. Sci. USA 93:9921-25

Calvin WH, Stevens CF. 1968. Synaptic noise and other sources of randomness in motoneuron interspike intervals. J. Neurophysiol. 31:574-87

Carew TJ, Hawkins RD, Abrams TW, Kandel ER. 1984. A test of Hebb's postulate at identified synapses which mediate classical conditioning in Aplysia. J. Neurosci. 4:1217-24

Carew TJ, Walters ET, Kandel ER. 1981. Classical conditioning in a simple withdrawal reflex in Aplysia californica. J. Neurosci. 1:142637

Carr CE. 1993. Processing of temporal information in the brain. Annu. Rev. Neurosci. 16:223-43

Cash S, Zucker RS, Poo M-m. 1996. Spread of synaptic depression mediated by presynaptic cytoplasmic signaling. Science 272:9981001

Clark GA, Hawkins RD, Kandel ER. 1994. Activity-dependent enhancement of presynaptic facilitation provides a cellular mechanism for the temporal specificity of classical conditioning in Aplysia. Learn. Mem. 1:24357

Clark GA, Kandel ER. 1993. Induction of longterm facilitation in Aplysia sensory neurons by local application of serotonin to remote synapses. Proc. Natl. Acad. Sci. USA 90:11411-15 
Collingridge GL, Kehl SJ, McLennan H. 1983. Excitatory amino acids in synaptic transmission in the Schaffer collateral-commissural pathway of the rat hippocampus. J. Physiol. 334:33-46

Constantine-Paton M, Cline HT, Debski E. 1990. Patterned activity, synaptic convergence, and the NMDA receptor in developing visual pathways. Annu. Rev. Neurosci. 13:129-54

Cowan AI, Stricker C, Reece LJ, Redman SJ. 1998. Long-term plasticity at excitatory synapses on aspinous interneurons in area CA1 lacks synaptic specificity. J. Neurophysiol. 79:13-20

Crair MC, Gillespie DC, Stryker MP. 1998. The role of visual experience in the development of columns in cat visual cortex. Science 279:566-70

Crowley JC, Katz LC. 1999. Development of ocular dominance columns in the absence of retinal input. Nat. Neurosci. 2:1125-30

Dan Y, Alonso JM, Usrey WM, Reid RC. 1998. Coding of visual information by precisely correlated spikes in the lateral geniculate nucleus. Nat. Neurosci. 1:501-7

Debanne D, Gahwiler BH, Thompson SM. 1998. Long-term synaptic plasticity between pairs of individual CA3 pyramidal cells in rat hippocampal slice cultures. J. Physiol. 507:237-47

deCharms RC, Merzenich MM. 1996. Primary cortical representation of sounds by the coordination of action-potential timing. Nature 381:610-13

Diesmann M, Gewaltig MO, Aertsen A. 1999. Stable propagation of synchronous spiking in cortical neural networks. Nature 402:529-33

Dudek SM, Bear MF. 1992. Homosynaptic long-term depression in area CA1 of hippocampus and effects of N-methyl-Daspartate receptor blockade. Proc. Natl. Acad. Sci. USA 89:4363-67

Dunwiddie T, Lynch G. 1978. Long-term potentiation and depression of synaptic responses in the rat hippocampus: localization and frequency dependency. J. Physiol. 276:353-67
Egger V, Feldmeyer D, Sakmann B. 1999. Coincidence detection and changes of synaptic efficacy in spiny stellate neurons in rat barrel cortex. Nat. Neurosci. 2:1098-105

Emptage NJ, Carew TJ. 1993. Long-term synaptic facilitation in the absence of shortterm facilitation in Aplysia neurons. Science 262:253-56

Engert F, Bonhoeffer T. 1997. Synapse specificity of long-term potentiation breaks down at short distances. Nature 388:279-84

Erwin E, Miller KD. 1998. Correlation-based development of ocularly matched orientation and ocular dominance maps: determination of required input activities. J. Neurosci. 18:9870-95

Fitzsimonds RM, Poo M-m. 1998. Retrograde signaling in the development and modification of synapses. Physiol. Rev. 78:14370

Fitzsimonds RM, Song H-j, Poo M-m. 1997. Propagation of activity-dependent synaptic depression in simple neural networks. Nature 388:439-48

Fregnac Y, Bienenstock E. 1998. Correlational models of synaptic plasticity: development, learning, and cortical dynamics of mental representations. In Mechanistic Relationships Between Development and Learning, ed. T Carew, R Menzel, C Shatz. pp. 11348. New York: Wiley

Gerstner W, Abbott LF. 1997. Learning navigational maps through potentiation and modulation of hippocampal place cells. J. Comput. Neurosci. 4:79-94

Gerstner W, Kempter R, van Hemmen JL, Wagner H. 1996. A neuronal learning rule for sub-millisecond temporal coding. Nature 383:76-81

Goda Y, Stevens CF. 1996. Long-term depression properties in a simple system. Neuron 16:103-11

Gustafsson B, Wigström H. 1986. Hippocampal long-lasting potentiation produced by pairing single volleys and brief conditioning tetani evoked in separate afferents. J. Neurosci. 6:1575-82 
Gustafsson B, Wigström H, Abraham WC, Huang YY. 1987. Long-term potentiation in the hippocampus using depolarizing current pulses as the conditioning stimulus to single volley synaptic potentials. J. Neurosci. 7:774-80

Hawkins RD, Abrams TW, Carew TJ, Kandel ER. 1983. A cellular mechanism of classical conditioning in Aplysia: activity-dependent amplification of presynaptic facilitation. Science 219:400-5

Hebb D. 1949. The Organization of Behavior. New York: Wiley

Hempel CM, Vincent P, Adams SR, Tsien RY, Selverston AI. 1996. Spatio-temporal dynamics of cyclic AMP signals in an intact neural circuit. Nature 384:166-69

Higashima M, Yamamoto C. 1985. Two components of long-term potentiation in mossy fiber-induced excitation in hippocampus. Exp. Neurol. 90:529-39

Hirsch JC, Barrionuevo G, Crepel F. 1992. Homo- and heterosynaptic changes in efficacy are expressed in prefrontal neurons: an in vitro study in the rat. Synapse 12:82-85

Hoffman DA, Magee JC, Colbert CM, Johnston D. 1997. K+ channel regulation of signal propagation in dendrites of hippocampal pyramidal neurons. Nature 387:869-75

Hollmann M, Heinemann S. 1994. Cloned glutamate receptors. Annu. Rev. Neurosci. 17:31-108

Hopfield JJ. 1995. Pattern recognition computation using action potential timing for stimulus representation. Nature 376:33-36

Horton JC, Hocking DR. 1996. An adult-like pattern of ocular dominance columns in striate cortex of newborn monkeys prior to visual experience. J. Neurosci. 16:1791-807

Hubel DH, Wiesel TN. 1965. Binocular interaction in striate cortex of kittens reared with artificial squint. J. Neurophysiol. 28:1041-59

Ito M, Sakurai M, Tongroach P. 1982. Climbing fibre induced depression of both mossy fibre responsiveness and glutamate sensitivity of cerebellar Purkinje cells. J. Physiol. 324:113-34
Jahr CE, Stevens CF. 1987. Glutamate activates multiple single channel conductances in hippocampal neurons. Nature 325:5225

Jeffress LA. 1948. A place theory of sound localization. J. Comp. Physiol. Psychol. 41:3539

Johnston D, Magee JC, Colbert CM, Cristie BR. 1996. Active properties of neuronal dendrites. Annu. Rev. Neurosci. 19:165-86

Katz LC, Shatz CJ. 1996. Synaptic activity and the construction of cortical circuits. Science 274:1133-38

Kelso SR, Brown TH. 1986. Differential conditioning of associative synaptic enhancement in hippocampal brain slices. Science 232:8587

Kelso SR, Ganong AH, Brown TH. 1986. Hebbian synapses in hippocampus. Proc. Natl. Acad. Sci. USA 83:5326-30

Kempter R, Gerstner W, van Hemmen JL. 2000. Hebbian learning and spiking neurons. Phys. Rev. E 59. In press

Koester HJ, Sakmann B. 1998. Calcium dynamics in single spines during coincident preand postsynaptic activity depend on relative timing of back-propagating action potentials and subthreshold excitatory postsynaptic potentials Proc. Natl. Acad. Sci. USA 95:9596601

Kossel A, Bonhoeffer T, Bolz J. 1990. NonHebbian synapses in rat visual cortex. NeuroReport 1:115-18

Kuznetsov SA, Langford GM, Weiss DG. 1992. Actin-dependent organelle movement in squid axoplasm. Nature 356:722-25

Lasser-Ross N, Ross WN. 1992. Imaging voltage and synaptically activated sodium transients in cerebellar Purkinje cells. Proc. $R$. Soc. London Ser. B 247:35-39

Laurent G. 1997. Olfactory processing: maps, time and codes. Curr. Opin. Neurobiol. 7:547-53

Lechner HA, Byrne JH. 1998. New perspectives on classical conditioning: a synthesis of Hebbian and non-Hebbian mechanisms. Neuron 20:355-58 
Levy WB, Steward O. 1979. Synapses as associative memory elements in the hippocampal formation. Brain Res. 175:233-45

Levy WB, Steward O. 1983. Temporal contiguity requirements for long-term associative potentiation/depression in the hippocampus. Neuroscience 8:791-97

Lin XY, Glanzman DL. 1994. Hebbian induction of long-term potentiation of Aplysia sensorimotor synapses: partial requirement for activation of an NMDA-related receptor. Proc. R. Soc. London Ser. B 255:21521

Linden DJ. 1999. The return of the spike: postsynaptic action potentials and the induction of LTP and LTD. Neuron 22:661-66

Linden DJ, Connor JA. 1995. Long-term synaptic depression. Annu. Rev. Neurosci. 18:31957

Lisman J. 1989. A mechanism for the Hebb and the anti-Hebb processes underlying learning and memory. Proc. Natl. Acad. Sci. USA 86:9574-78

Lo YJ, Poo MM. 1991. Activity-dependent synaptic competition in vitro: heterosynaptic suppression of developing synapses. Science 254:1019-22

Lux HD, Veselovsky NS. 1994. Glutamateproduced long-term potentiation by selective challenge of presynaptic neurons in rat hippocampal cultures. Neurosci. Lett. 178:23134

Lynch GS, Dunwiddie T, Gribkoff V. 1977. Heterosynaptic depression: a postsynaptic correlate of long-term potentiation. Nature 266:737-39

Maass W, Bishop CM, eds. 1999. Pulsed Neural Network. Cambridge, MA: MIT Press. $377 \mathrm{pp}$.

Maccaferri G, Toth K, McBain CJ. 1998. Target-specific expression of presynaptic mossy fiber plasticity. Science 279:1368-70

Magee JC, Johnston D. 1997. A synaptically controlled, associative signal for Hebbian plasticity in hippocampal neurons. Science 275:209-13

Mainen ZF, Sejnowski TJ. 1995. Reliability of spike timing in neocortical neurons. Science 268:1503-6

Malenka RC, Kauer JA, Perkel DJ, Mauk MD, Kelly PT, et al. 1989. An essential role for postsynaptic calmodulin and protein kinase activity in long-term potentiation. Nature 340:554-57

Malenka RC, Nicoll RA. 1999. Long-term potentiation-a decade of progress. Science 285:1870-74

Malinow R, Schulman H, Tsien RW. 1989. Inhibition of postsynaptic PKC or CaMKII blocks induction but not expression of LTP. Science 245:862-66

Markram H, Lubke J, Frotscher M, Sakmann B. 1997. Regulation of synaptic efficacy by coincidence of postsynaptic APs and EPSPs. Science 275:213-15

Marsálek P, Koch C, Maunsell J. 1997. On the relationship between synaptic input and spike output jitter in individual neurons. Proc. Natl. Acad. Sci. USA 94:735-40

Mayer ML, Westbrook GL, Guthrie PB. 1984. Voltage-dependent block by $\mathrm{Mg}^{2+}$ of NMDA responses in spinal cord neurones. Nature 309:261-63

McMahon LL, Kauer JA. 1997. Hippocampal interneurons express a novel form of synaptic plasticity. Neuron 18:295-305

McNaughton BL, Douglas RM, Goddard GV. 1978. Synaptic enhancement in fascia dentata: cooperativity among coactive afferents. Brain Res. 157:277-93

Mehta MR, Barnes CA, McNaughton BL. 1997. Experience-dependent, asymmetric expansion of hippocampal place fields. Proc. Natl. Acad. Sci. USA 94:8918-21

Mehta MR, Quirk MC, Wilson MA. 2000. Experience-dependent asymmetric shape of hippocampal receptive fields. Neuron 25:707-15

Miller KD. 1994. A model for the development of simple cell receptive fields and the ordered arrangement of orientation columns through activity-dependent competition between $\mathrm{ON}$ - and OFF-center inputs. $\mathrm{J}$. Neurosci. 14:409-41 
Miller KD, Keller JB, Stryker MP. 1989. Ocular dominance column development: analysis and simulation. Science 245:605-15

Milner B, Squire LR, Kandel ER. 1998. Cognitive neuroscience and the study of memory. Neuron 20:445-68

Minai AA, Levy WB. 1993. Sequence learning in a single trial. INNS World Congr. Neural Netw. 2:505-8

Misgeld U, Sarvey JM, Klee MR. 1979. Heterosynaptic postactivation potentiation in hippocampal CA 3 neurons: long-term changes of the postsynaptic potentials. Exp. Brain Res. 37:217-29

Montague PR, Sejnowski TJ. 1994. The predictive brain: temporal coincidence and temporal order in synaptic learning mechanisms Learn. Mem. 1:1-33

Moore JW, Choi J-S, Brunzell DH. 1998. Predictive timing under temporal uncertainty: the time derivative model of the conditioned response. In Timing of Behavior, ed. DA Risenbaum, CE Collyer, pp. 3-34. Cambridge, MA: MIT Press

Mulkey RM, Endo S, Shenolikar S, Malenka RC. 1994. Involvement of a calcineurin/inhibitor-1 phosphatase cascade in hippocampal long-term depression. Nature 369:486-88

Mulkey RM, Malenka RC. 1992. Mechanisms underlying induction of homosynaptic longterm depression in area CA1 of the hippocampus. Neuron 9:967-75

Muller D, Hefft S, Figurov A. 1995. Heterosynaptic interactions between LTP and LTD in CA1 hippocampal slices. Neuron 14:599605

Murphy GG, Glanzman DL. 1997. Mediation of classical conditioning in Aplysia californica by long-term potentiation of sensorimotor synapses. Science 278:467-71

Nakamura T, Barbara JG, Nakamura K, Ross WN. 1999. Synergistic release of $\mathrm{Ca}^{2+}$ from IP3-sensitive stores evoked by synaptic activation of mGluRs paired with backpropagating action potentials. Neuron 24:727-37

Nicoll RA, Malenka RC. 1997. Neurobiology.
Long-distance long-term depression. Nature 388:427-28

Nishiyama M, Hong K, Mikoshiba K, Poo M-m, Kato K. 2000. Calcium release from internal stores regulates polarity and input specificity of synaptic modification. Nature. In press

Nowak L, Bregestovski P, Ascher P, Herbet A, Prochiantz A. 1984. Magnesium gates glutamate-activated channels in mouse central neurones. Nature 307:462-65

Paulsen O, Sejnowski TJ. 2000. Natural patterns of activity and long-term synaptic plasticity. Curr. Opin. Neurobiol. 10:172-79

Penn AA, Riquelme PA, Feller MB, Shatz CJ. 1998. Competition in retinogeniculate patterning driven by spontaneous activity. Science 279:2108-12

Perkel DH, Bullock TH. 1968. Neural coding. Neurosci. Res. Prog. Sum. 3:405-527

Purves D. 1975. Functional and structural changes in mammalian sympathetic neurones following interruption of their axons. J. Physiol. 252:429-63

Rao RPN, Sejnowski TJ. 2000. Predictive learning of temporal sequences in recurrent neocortical circuits In Advances in Neural Information Processing Systems, Vol. 12, ed. SA Solla, TK Leen, K-R Muller. Cambridge, MA: MIT Press. In press

Regehr WG, Konnerth A, Armstrong CM. 1992. Sodium action potentials in the dendrites of cerebellar Purkinje cells. Proc. Natl. Acad. Sci. USA 89:5492-96

Reyes A, Lujan R, Burnashev N, Somogyi P, Sakmann B. 1998. Target-cell-specific facilitation and depression in neocortical circuits. Nat. Neurosci. 1:279-85

Riehle A, Grün S, Diesmann M, Aertsen A. 1997. Spike synchronization and rate modulation differentially involved in motor cortical function. Science 278:1950-53

Rieke F, Warland D, de Ruyter van Steveninck R, Bialek W. 1997. Spikes: Exploring the Neural Code. Cambridge, MA: MIT Press. 395 pp.

Roberts PD. 1999. Computational consequences of temporally asymmetric learning 
rules. I. Differential hebbian learning. $J$. Comput. Neurosci. 7:235-46

Roelfsema PR, Engel AK, König P, Singer W. 1997. Visuomotor integration is associated with zero time-lag synchronization among cortical areas. Nature 385:157-61

Rolls ET, Treves A. 1998. Neural Networks and Brain Function. New York: Oxford Univ. Press

Rumelhart DE, Hinton GE, Williams RJ. 1986a. Learning internal representations by error propagation. In Parallel Distributed Processing, ed. JA Feldman, PJ Hayes, DE Rumelhart. 1:318-62. Cambridge, MA: MIT Press

Rumelhart DE, Hinton GE, Williams RJ. 1986b. Learning representation by back-propagating errors. Nature 323:533-36

Sastry BR, Goh JW, Auyeung A. 1986. Associative induction of posttetanic and long-term potentiation in CA1 neurons of rat hippocampus. Science 232:988-90

Schinder AF, Berninger B, Poo M. 2000. Postsynaptic target specificity of neurotrophininduced presynaptic potentiation. Neuron 25:151-63

Schuman EM, Madison DV. 1994. Locally distributed synaptic potentiation in the hippocampus. Science 263:532-36

Sejnowski TJ. 1977a. Statistical constraints on synaptic plasticity. J. Theor. Biol. 69:385-89

Sejnowski TJ. 1977b. Storing covariance with nonlinearly interacting neurons. J. Math. Biol. 4:303-21

Sejnowski TJ. 1999. The book of Hebb. Neuron 24:773-76

Sejnowski TJ, Tesauro G. 1989. The Hebb rule for synaptic plasticity: algorithms and implementations. In Neural Models of Plasticity: Experimental and Theoretical Approaches, ed. John H. Byrne. pp. 94-103. San Diego, CA: Academic

Senn W, Markram H, Tsodyks M. 2000. An algorithm for modifying neurotransmitter release probability based on pre- and postsynaptic spike timing. Neural Comput. In press

Silva AJ, Stevens CF, Tonegawa S, Wang Y.
1992. Deficient hippocampal long-term potentiation in alpha-calcium-calmodulin kinase II mutant mice. Science 257:201-6

Singer W. 1999. Time as coding space? Curr. Opin. Neurobiol. 9:189-94

Singer W, Gray CM. 1995. Visual feature integration and the temporal correlation hypothesis Annu. Rev. Neurosci. 18:555-86

Squire LR. 1987. Memory and Brain. New York: Oxford Univ. Press

Staubli UV, Ji ZX. 1996. The induction of homo- vs. heterosynaptic LTD in area CA1 of hippocampal slices from adult rats. Brain Res. 714:169-76

Stent GS. 1973. A physiological mechanism for Hebb's postulate of learning. Proc. Natl. Acad. Sci. USA 70:997-1001

Stevens CF. 1996. Strengths and weaknesses in memory. Nature 381:471-72

Stevens CF, Zador AM. 1998. Input synchrony and the irregular firing of cortical neurons. Nat. Neurosci. 1:210-17

Stryker MP, Strickland SL. 1984. Physiological segregation of ocular dominance columns depends on patterns of afferent activity. Invest. Ophthalmol. Suppl. 25:278

Stuart GJ, Sakmann B. 1994. Active propagation of somatic action potentials into neocortical pyramidal cell dendrites. Nature 367:69-72

Sutton RS, Barto AG. 1981. Toward a modern theory of adaptive networks: expectation and prediction. Psychol. Rev. 88:135-70

Tank DW, Hopfield JJ. 1987. Neural computation by concentrating information in time. Proc. Natl. Acad. Sci. USA 84:1896-900

Tao HW, Zhang LI, Bi G-q, Poo M-m. 2000. Selective presynaptic propagation of longterm potentiation in defined neural networks. J. Neurosci. 20:3233-43

Tesauro G. 1986. Simple neural models of classical conditioning. Biol. Cybern. 55:187-200

Teyler TJ, DiScenna P. 1987. Long-term potentiation. Annu. Rev. Neurosci. 10:131-61

Thompson RF, Krupa DJ. 1994. Organization of memory traces in the mammalian brain. Annu. Rev. Neurosci. 17:519-49 
Tsumoto T, Suda K. 1979. Cross-depression: an electrophysiological manifestation of binocular competition in the developing visual cortex. Brain Res. 168:190-94

Tzounopoulos T, Janz R, Südhof TC, Nicoll RA, Malenka RC. 1998. A role for cAMP in long-term depression at hippocampal mossy fiber synapses. Neuron 21:837-45

Vale RD, Reese TS, Sheetz MP. 1985. Identification of a novel force-generating protein, kinesin, involved in microtubule-based motility. Cell 42:39-50

Vallee RB, Bloom GS. 1991. Mechanisms of fast and slow axonal transport. Annu. Rev. Neurosci. 14:59-92

Walters ET, Byrne JH. 1983. Associative conditioning of single sensory neurons suggests a cellular mechanism for learning. Science 219:405-8

Weliky M, Katz LC. 1997. Disruption of orientation tuning in visual cortex by artificially correlated neuronal activity. Nature 386:680-85

Wiesel TN, Hubel DH. 1963. Single cell responses in striate cortex of kittens deprived of vision in one eye. J. Neurophysiol. 26:10037

Wigström H, Gustafsson B, Huang YY, Abraham WC. 1986. Hippocampal long- term potentiation is induced by pairing single afferent volleys with intracellularly injected depolarizing current pulses. Acta Physiol. Scand. 126:317-19
Wong RO, Chernjavsky A, Smith SJ, Shatz CJ. 1995. Early functional neural networks in the developing retina. Nature 374:716-18

Yamamoto C, Chujo T. 1978. Long-term potentiation in thin hippocampal sections studied by intracellular and extracellular recordings. Exp. Neurol. 58:242-50

Yang SN, Tang YG, Zucker RS. 1999. Selective induction of LTP and LTD by postsynaptic $\left[\mathrm{Ca}^{2+}\right]$ elevation. J. Neurophysiol. 81:78187

Yeckel MF, Kapur A, Johnston D. 1999. Multiple forms of LTP in hippocampal CA3 neurons use a common postsynaptic mechanism. Nat. Neurosci. 2:625-33

Yovell Y, Abrams TW. 1992. Temporal asymmetry in activation of Aplysia adenylyl cyclase by calcium and transmitter may explain temporal requirements of conditioning. Proc. Natl. Acad. Sci. USA 89:6526-30

Yovell Y, Kandel ER, Dudai Y, Abrams TW. 1992. A quantitative study of the $\mathrm{Ca}^{2+} /$ calmodulin sensitivity of adenylyl cyclase in Aplysia, Drosophila, and rat. J. Neurochem. 59:1736-44

Zhang LI, Tao HW, Holt CE, Harris WA, Poo Mm. 1998. A critical window for cooperation and competition among developing retinotectal synapses. Nature 395:37-44

Zheng JQ, Zheng Z, Poo M. 1994. Long-range signaling in growing neurons after local elevation of cyclic AMP-dependent activity. $J$. Cell Biol. 127:1693-701 